\title{
News Note
}

\section{MULTIPLE INPUT PRODUCTIVITY INDEXES* \\ Keith E. McKee}

IITRI Manufacturing Productivity Center Chicago, Illinois (USA) (Received: January 20, 1985)

For several years the American Productivity Center (APC) has been publishing an index under this title. The most recent issue, Volume 5, Number 2, dated November 1984, is a valuable source of data that should be obtained and reviewed by all of those interested in productivity. This short article uses data from that publication with views and opinions added by myself.

The cover of this report contains the following data on 1983 productivity changes. period is included. It is interesting to note that only six economic sectors have experienced a decrease in productivity over the two periods considered:

- Petroleum with a $3.3 \%$ decrease in $1973-79$ and a $4.0 \%$ decrease in 1979-83. It is interesting to note that total factor productivity has decreased significantly since the energy crisis of 1973. Does this imply that the petroleum industry has since then been working with less desirable input materials, or does it indicate that in a period of rapidly rising energy costs there has been little attention to improving productivity? It might be noted that the situation has worsened from 1973-79 to $1979-83$.

- Mining has decreased by $4.1 \%$ in $1973-79$ and $1.9 \%$ in 1979-83. Presumably these decreases are related to en-

1983 Productivity Growth Rates (annual percent of change)

\begin{tabular}{lcccc}
\hline & $\begin{array}{c}\text { Total Factor } \\
\text { Productivity }\end{array}$ & $\begin{array}{c}\text { Labor } \\
\text { Productivity }\end{array}$ & $\begin{array}{c}\text { Capital } \\
\text { Productivity }\end{array}$ & $\begin{array}{c}\text { Capital/Labor } \\
\text { Ratio }\end{array}$ \\
\hline $\begin{array}{l}\text { Private business } \\
\text { economy }\end{array}$ & $2.5 \%$ & $2.7 \%$ & $2.0 \%$ & $0.7 \%$ \\
Segments: & -7.7 & -10.2 & -5.4 & -5.2 \\
$\quad$ Farming & 6.3 & 6.2 & 6.5 & -0.3 \\
$\quad$ Manufacturing & 1.3 & 1.9 & 0.4 & 1.5 \\
$\quad$ Non-farm/non- & & & & \\
$\quad$ manufacturing & 4.7 & 4.4 & 5.4 & -1.0 \\
$\quad$ Sectors: & 1.0 & 1.6 & 0.1 & 1.5 \\
$\quad$ Goods-producing & & & & \\
$\quad$ Services-producing & & & & \\
\hline
\end{tabular}

As often mentioned in previous issues of Frontiers, we seriously question productivity changes over a short period as having much significance (and we consider a year to be a short period). This table offers a particularly good example-based on this table farming is clearly the major problem within the U.S. economy. For a variety of reasons this is not at all true and conclusions reached by considering only 1983 data can be very misleading.

This table again illustrates that total factor productivity does not provide insight much different than that provided by the more traditional labor productivity growth rates. There is a broad belief that somehow total factor data are much more meaningful and it may well be, but only occasionally do the trends differ significantly. It may be better to use total factor productivity but, in general, little understanding is lost if only labor productivity data are available and used.

Other details are excerpted from Table IIIa in the report. This is the total factor productivity based on average annual rate of change for 1973-79 and 1979-83. Overall a 10-year

* Reprinted from Manufacturing Productivity Frontiers 9, No. 1 23-26 January, 1985, by kind permission of the IIT Research Institute, Chicago, Illinois (U.S.A.) vironmental and safety requirements that have made it more difficult to mine. Here there is an improvement (at least a lessening of the negative total factor productivity growth).

- Construction has decreased $3.0 \%$ in $1973-79$ and $1.5 \%$ in 1979-83. Construction has long had a productivity problem (it decreased $1.0 \%$ annually between 1965 and 1973). A variety of explanations have been offered for the long-term decrease in construction productivity. Frankly none of these are totally satisfactory and this remains at least to this author, an unanswered question and we do not even have a hypothesis we can believe.

- Primary metals total factor productivity decreased $2 \%$ in 1973-79 and $1.9 \%$ in 1979-83. This represents a long-term problem and one which has impacted on the international competitiveness of this industry. There is a broad perception that this industry has failed to emphasize productivity and so brought this decrease on itself. Within the past few years this industry has been hit by a decrease in demand and a worldwide excess capacity.

- Finance and insurance shows a decrease of $1.1 \%$ in 1973-79 and $2.0 \%$ in $1979-83$. In a growth industry where there has been a major introduction of computers, this decrease is almost unbelievable. Does someone have an explanation? 
- Public utilities saw a $1.0 \%$ decrease in $1973-79$ and a $1.9 \%$ in 1979-83. Again this decrease started with the energy crisis and the questions raised relating to the petroleum industry are relevant.

Thus far we have looked at the negatives and that is really unfair. Many sectors of the economy have done well. Approximately three times the sectors have shown total factor productivity in both periods as the number that shows negative. Comments on each would be boring and this writer is incompetent to do so in any case. A few sectors are considered below.

Farming increased $1.8 \%$ in $1973-79$ and $0.3 \%$ in $1979-83$. Perhaps after decades of productivity improvement, productivity in farming is going to plateau. U.S. farmers are approximately twice as productive as those in France and England and four times those in Germany and Japan. Our earlier comments on the dangers of using short term productivity measurements are clearly illustrated by this example. The 1983 performance for the farming sector would appear to be an anomalycertainly to be ignored until and unless there is a continuation of this one-year trend.

- Textiles $(3.7 \%$ and $3.4 \%$ increases) and apparel $(3.1 \%$ and $2.9 \%$ ) have a long-term history of productivity improvement and have been able to remain competitive with producers in other nations.

- Electrical machinery with $3.2 \%$ and $3.0 \%$ increases represents another industry which has improved productivity over the long haul and has by-and-large managed to remain competitive with foreign companies.

U.S.A. with excellent, effective communication. By-and-large these increases demonstrate the impact of ever-improving technology.

- Trade with $0.7 \%$ and $1.4 \%$ increases represents improvements in a sector of the economy which has shown long-term improvement.

Productivity growth rates always represent an interesting set of data. The interpretation of the data is even more interesting because the same data can be interpreted in different ways based on the bias and background of the writer.

The data used in this paper are taken from the APC report referenced earlier. Our thanks to APC - this is a useful report and one of considerable value. We hope that some of our readers will obtain the report and we would be interested in alternative interpretations. 